\title{
Authentic assessment for advanced undergraduate students
}

\author{
D. G. Mallet* \\ (Received 6 October 2005; revised 3 August 2006)
}

\begin{abstract}
A novel assessment program was implemented in an upper level mathematical modelling subject for a small group of advanced undergraduate students of applied mathematics and engineering. The students were all enrolled in undergraduate degree programs at the selective private colleges, Harvey Mudd College and Pitzer College, in California. The subject was called Mathematics and Sport and introduced the students to various techniques and strategies of mathematical modelling and related research using a number of interesting applications of mathematics to sports. The assessment program was designed to provide the students with authentic activities preparing them for their future work as graduate students and researchers. The
\end{abstract}

*School of Mathematical Sciences, Queensland University of Technology, Brisbane, Australia and Department of Mathematics, Harvey Mudd College, Claremont, CA, USA. http://www.maths.qut.edu.au/profiles/mallet/

See http://anziamj.austms.org.au/V47EMAC2005/Mallet for this article, (C) Austral. Mathematical Soc. 2007. Published January 5, 2007. ISSN 1446-8735 
program included a mock "conference day" for which students prepared papers and presented a seminar. The written paper and the seminar were scaffolded by instruction in such writing and presentation as well as activities to encourage free thinking and creative interpretation of problems throughout the semester. The assessment scheme proved to be both popular with students and effective, in that continuous components prepared the students for the requirements of terminating assessment items. The students' papers proved to be well-written, thoughtful and, to some extent, illustrated the students' development as researchers over the course of the subject. Unfortunately, the oral presentations were not of the same high standard for a number of reasons including the level of instruction in this subject and also previous experience in presenting orally. This article offers a description of the novel assessment program and the results of its implementation in order to provide guideposts for others confronted with similar student groups.

\section{Contents}

1 Introduction

2 The students and the course

3 Assessment strategy

4 Impact on students

C534

5 Findings and conclusion

References 
To solve the equation we will first integrate with respect to time to obtain the velocity of the projectile, v. Having done this, we integrate with respect to $t$ again to solve for the displacement of the projectile as a function of time.

Think: Note in the equation for velocity that the horizontal component is a constant, but the vertical component is not. Why is this the case?

Figure 1: An example of a 'think' problem taken from the workbook chapter discussing simple projectile motion. Space is provided for students to complete calculations and note any useful thoughts.

\section{Introduction}

In a recent course offering, Mathematics and Sport, an assessment structure was implemented that included the assessment of class workbooks, written research papers and oral presentations of research. While the use of research papers and oral presentations may be a reasonably common practice, the use and assessment of workbooks in advanced university mathematics classrooms is quite unusual, particularly in the experience of the author. Due to the structure of the remainder of the assessment programme, two terminating assessment items, it was important to include a component of continuous assessment via the workbook. It was found that students enjoyed the stimulating 'think' problems used in the workbook (see Figure 1). They believed that these activities improved the level of insight that they obtained during the course and that they were able to demonstrate in their mock journal articles. 
In the remainder of this article, the assessment items and their impacts on students' attitudes and learning are discussed. In the following section, the assessment context is described before a discussion of the assessment programme is given in order to provide a background to the ensuing discussion. Following the background explanation, the impact of the assessment items on student attitudes and performance is considered before a consideration of the strengths and weaknesses of the assessment items is presented.

\section{The students and the course}

Provided in this section is a short summary of the students and the instructional program in order to form a background to the discussion of the assessment items. The nine students taking the course were either junior or senior science, mathematics and engineering students at the highly selective undergraduate institutions Harvey Mudd College (HMC) and Pitzer College in Claremont, California. All students in this class were Americans, but came to HMC from different socio-economic and geographic backgrounds. A common characteristic of the students is that they are all very gifted mathematically.

The course Mathematics and Sport was a seven week course introducing students to interesting sporting applications of mathematics and the skills required to construct, analyse and present mathematical models. In brief, the major assessment tasks required of the students included a mock mathematical modelling journal article on a topic of their choice (in mathematical modelling of sport) coupled with an oral presentation of the same work to a group of their peers and professors. The third component of the assessment programme was one that is not often employed in advanced undergraduate mathematics classes - a workbook with activities related to classroom lectures that are completed by students after each lecture (see for example, Figure 2). The workbook item will be discussed in more detail later in this 
Task: Show that the above expression for the position of the projectile reduces to the no drag result as the drag coefficient approaches zero.

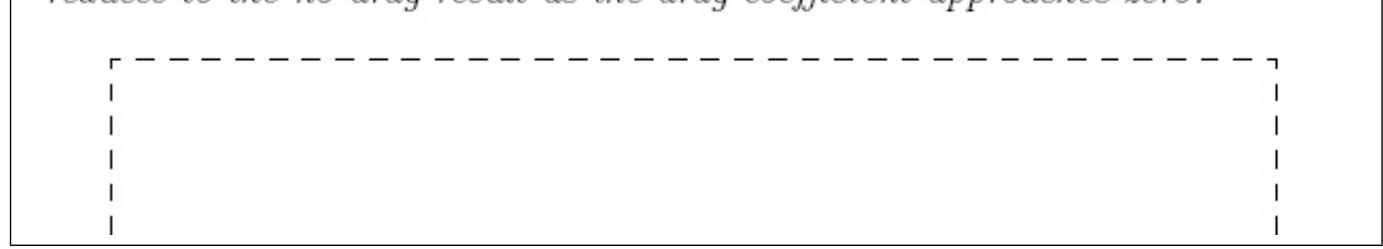

Figure 2: Outside of class time, students were required to complete tasks related to classroom lectures which aligned their thoughts and work directions.

article. References to such assessment tasks are scarce, but include a so called 'novel' first-year analysis course at University of Warwick where the workbook has been implemented specifically to allow students to cope with a traditionally difficult subject [9].

All of the students in the course considered here are well above average in terms of mathematical ability. Indicative of the general standard of HMC students is that the 2003/4 incoming class achieved an average SAT math score of 750 compared with the national average of 519 [6]. Furthermore, in the first two or three years of college education, the students were provided with the fundamental and advanced concepts of many aspects of mathematics. In this course, an attempt was made to provide the students with an introductory level of training in the skills of mathematical modelling research and mathematical communication. The assessment programme as a whole was designed to guide the students in developing these skills and also to provide a measure of development over the duration of the course. 


\section{Assessment strategy}

Briefly outlined earlier, the assessment strategy for Mathematics and Sport comprised three items.

1. Mock journal article (70\% of grade). A mathematical modelling paper presenting a model of some sport related process (such as the path of a basketball to the hoop), written in the style of international, peerreviewed journals.

2. Oral seminar (20\% of grade). An oral presentation of approximately 15 minutes, discussing the research presented in the mock journal article.

3. Class workbook (10\% of grade). Including exercises to fill in gaps in class activities, finish mathematical questions, but most importantly, to think about, discuss and reflect on ideas extending the work carried out in class.

The mock journal article and the oral seminar formed the dominantly authentic parts of the assessment program in that they required the students to effectively use acquired knowledge in mathematical communication to practice abilities required by real-world mathematicians $[8,11]$. Both were presented and then assessed at the end of the lecture program.

Item number three is of particular interest as it is not used regularly by the author and the perceived resulting impact on student learning is worthy of note. The class workbook is designed to be a type of portfolio of a student's work and to that end it is a focused collection of work to demonstrate achievement and growth in learning [1]. Doubling as abbreviated lecture notes, the workbook provided students with the opportunity to give written and graphical (such as plots) examples of their mathematical work, undertake personal reflection upon the work discussed in class, and think about 
Wrapping Task: Write a paragraph or two about what you think could make the mathematical results regarding optimum projection angles for maximum projectile range, incorrect. How and why would these things change the outcome of a projectile sport?

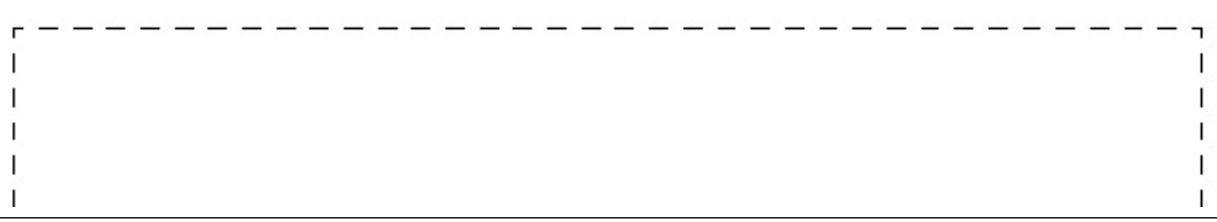

FIgURE 3: An example reflective summary task following a section discussing the importance of common sense in modelling projectiles.

ways of extending classroom work. The tasks required of students were similar in nature to the 'situational lessons' discussed by Pandey as emerging directions in authentic mathematics assessment [8].

The course was divided into seven content modules and associated with each of these was a separate workbook section. The students were required to:

- fill in gaps from classroom examples,

- complete traditional mathematical question tasks listed in the text,

- think critically and deeply about discussions in class and extensions to class activities,

- write reflective summaries of sections of classroom work (see Figure 3).

The workbook is an unusual assessment item for upper level undergraduate mathematics courses. Discussions with colleagues led to comments that 
the idea may be "childish" and inadequate to fully assess the learning of the students in an advanced level class such as Mathematics and Sport. It is therefore important to realise that the workbook is not meant to "fully" assess student learning, but instead to form part of a comprehensive assessment program.

The obvious reasons for choosing the workbook for assessment are that the instructor is able to keep track of what the students know over the length of the course and that the workbook promotes student reflection and critical thinking through a thoughtful choice of activities [1]. However, it is also important to note that the workbook appears to be a better choice over such alternatives as unadorned homework assignments, especially for an upper level class. While similar questions and critical thinking activities could be set for the students, it seems that the continuity and style of the portfolio/ workbook improve the input of the students and even increased the apparent sense of pride that students showed in their work.

In line with Crossroads in Mathematics [2], the initial adoption of this workbook assessment activity was to provide a form of frequent assessment. This was especially important given that the remaining two assessment items would only see the students being assessed after the course was completed, giving no possibility of feedback to help the students performance in the course. However, the use of portfolio style activities is also considered to motivate students and involve them in their own learning [1]. Based on informal student comments and the author's perception of student interest levels, the workbook task was at least successful from an observational point of view.

The students were required to complete the workbook activities for each module of the class within one week of completion of that module. However, they were encouraged to continue with the reflection and thinking activities throughout the seven weeks of the course. Upon submission, the students were graded using a rubric to which they had free access from the beginning of the course (see Figure 4). Using the rubric, along with additional comments 


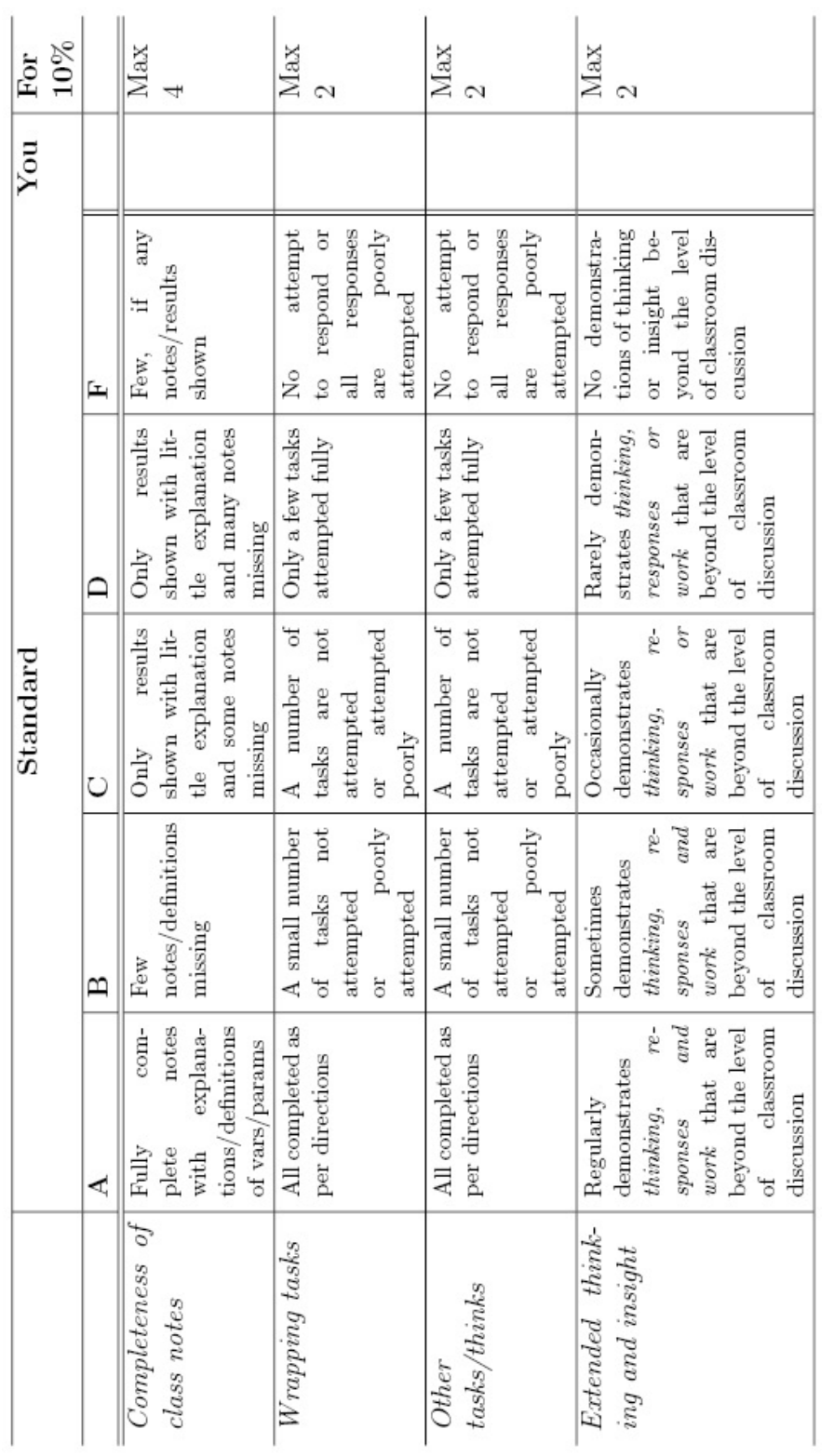

FiguRE 4: The workbook grading rubric. 
and interviews if necessary, feedback was provided to the students with an aim to effect learning improvements [3].

Comments and discussions with the student could be as simple as instructing them to complete questions and notes, or as deep as considering the student's thoughts and reflections on what was discussed in class. One favourable outcome of these discussions was when a student revealed an interest in pursuing undergraduate research related to a topic covered in class. The student has already formulated extended thoughts and theories related to sporting game theory and extensions to mathematical sociology.

Given that continuous feedback was facilitated through the grading rubric, it is important also to consider the choice of this item. Arter [1] states that clear and complete criteria for assessing students' performances are essential; for this reason, students were provided with the grading rubric early in the course and the workbook and other assessment items were discussed fully with students in the first lecture. Therefore the rubric conveys to students the requirements of the assessment activity. The rubric increases the validity of the workbook assessment by facilitating fairness, accuracy and consistency. All students are graded using the same criteria for the same activities and hence the rubric allows for appropriate assessments of student performance [7].

It seems fair to assume that researchers would reflect on their work and the work of others as part of a thoughtful research activity. In this way then, the workbook can also be seen as offering a form of authentic assessment for students intending to proceed to future employment as researchers. Written communication skills as well as reflective practice, a meta-cognitive function, are considered important as graduate capabilities [5]. Not only does this type of workbook develop attitudes of an active researcher, it also addresses elements of graduate capability frameworks which are of high importance in modern universities. 


\section{Impact on students}

Initially, the students of the course were concerned that with $90 \%$ of their final grade depending on the mock journal article and the oral presentation, there would not be enough feedback throughout the course to guide their final submissions. However, over the extent of the course eight of the students underwent distinct changes in their attitude toward the structure of the course as a whole and the assessment programme in particular.

A report by Saskatchewan Education [10] states that attitudes of students are shown in how they ask and answer questions, attempt problems, and approach new mathematical work. The report notes that written papers, oral presentations and collections of work are perfect ways to assess mathematics students' attitudes. In light of this, the assessment program implemented for Mathematics and Sport was ideal for assessing student attitudes. Throughout the course it was possible to gauge students' attitudes through their responses, reflections and answers to mathematics problems, all of which were provided in the workbook. In this way the workbook served as an effective index of students' attitudes.

With such a small class it was possible to personally interview the students both during and after the course. These interviews provided useful information relating to the students' feelings towards the course as a whole and the assessment program in particular.

Student interviews in week one, after being informed of the assessment structure, revealed that all students suspected the workbook activity may be rather simple and of little use in improving their learning and/or final grades. Furthermore, three students raised queries as to how the workbook - based on in class lectures - could be useful when the students are not given traditional examinations on that lecture material. In other words: "Why should we study something that we are not 'tested' on?" In the weeks to come, this view was to change for most students. However, one student did display a 
degree of 'blind faith' when mentioning that the activity must be somewhat relevant to the learning process and subsequent assessment since it was a required activity.

After three of the seven weeks of lectures, the students had been exposed to two and a half of the lecture topics, been assessed on one workbook module, and already been exposed to the full array of workbook activity types. At this point, a further series of student-instructor interviews were conducted and already it appeared that the attitudes of some students were shifting. Five of the students still showed signs of struggling with the concept of a mathematics course where their mathematical ability was not the principle indicator of learning or the skill to be assessed. However, over the weeks to follow, students reported that this feeling decreased somewhat and that they began to see the mathematics, which they already understood, as a medium through which the communication skills to which they were being exposed were passed.

Students also raised issues with tasks in the workbook asking them to 'think critically' or 'reflect on' some principle or application of mathematics. They were concerned that these were not 'mathematical' activities. For this reason, one half of a lecture period (about 35 minutes) was dedicated to a discussion of life as a mathematical researcher and what type of activities this regularly involved. This also coupled as a useful introduction to the period of time that students would spend writing their mock articles. The author gave students examples of how a mathematical biologist (the author's main field of research)

- examines biological literature,

- thinks critically about experimental problems and how they could be better explained in a theoretical/mathematical manner, and

- reflects on the models that he/she constructs and the resulting predictions and observations. 
While the students were not explicitly told why the half-lecture was being presented, one student offered a comment at the end of the class that they now understood why they needed to learn how to think and reflect, not just to 'do' mathematics problems. A number of other students were in agreement with this comment.

Following the conclusion of lectures and after final assessment, interviews of students were again conducted. Seven of the students commented that their attitude, in particular towards the workbook exercise, changed over the duration of the course. Most said that they began to see it as less of an inconvenient waste of time and more of a useful preparatory exercise when they began working on their mock journal articles. The students remarked that they could see the link between deeper, non mathematical thinking and reflecting, and the conduct of mathematical research quite early in the paper writing process. Six of those students also observed that they became more active in the class at around that same time.

Since this workbook type of assessment activity has not been used previously by the author, it is difficult to accurately measure its impact on student performance. However, the quality of the final submissions (mock paper and oral presentation) of the students was exceptional. Eight of the nine students displayed critical thinking skills, depth of perception and broad considerations all beyond levels expected by the instructor. The conclusion sections of the students' papers also showed evidence of development in their ability to reflect on what they were studying, including looking in tangential directions from the initial study, discussing possible problems, and why certain directions were taken in the solution of problems. Again it is difficult to measure the effect of the workbook on these final projects, but given the impact of the workbook on the students' attitudes and the students' revelations of how important reflecting and thinking are in the research process, it seems that there were indeed positive results. 


\section{$5 \quad$ Findings and conclusion}

This offering of Mathematics and Sport was the first for the instructor, and as a result the course as a whole and the assessment component are a first attempt. Therefore, both promising strengths and weaknesses to be improved were elucidated in this first staging of the course. A number of useful insights into the coupling of the course and its student cohort were also brought to light.

A particularly promising strength of the workbook assessment item was that students began to associate their success in the course or lack thereof with their own strengths and weaknesses, particularly in mathematical communication and thinking. Brosnan and Hartog [4] also found that such associations were helped by portfolio assessment. Furthermore, the workbook assessment item allowed the instructor to gauge student skills and development in communication and critical thinking over the entire length of the course, while the mock paper and oral presentation gave only end results.

The workbook was also a useful means for the instructor to evaluate and improve the course itself, as evidenced by the introduction of a lecture about 'life as a mathematical biologist'. The instructor observed the need to alter the lecture sequence and topics slightly, and as a result of the alterations, students' attitudes and understanding were improved.

While written papers and oral presentations are common and tested forms of course assessment, the workbook or portfolio seems to be quite rare in upper level, undergraduate mathematics courses. This may be due to the lack of 'hard' evidence of the improvements in learning due to the assessment of portfolios [1]. Another weakness of the workbook assessment item was the lack of familiarity that the instructor had with the students. It was difficult to accurately anticipate the level of critical thinking and reflection skills with which the students would enter the class. This weakness could be overcome in future offerings of the course and the subsequent tailoring of the workbook 
to the level of skill of particular student groups.

In summary, the rarely employed workbook portfolio was employed as part of an authentic assessment program in an advanced level undergraduate course - Mathematics and Sport. The workbook was used in an attempt to introduce students to mathematical communication, critical thinking and reflection. Such skills were required in order to prepare the students for their final assessment items, the oral seminar and mock journal article. Interviews with students both during and after the course indicated that over the period of the course their attitudes toward the workbook item changed in that they began to fully realise its relevance to their assessment and to life as a mathematician in general.

Without quantitative control data for students not using the workbook, it is difficult to measure its impact on students' raw-grade performances. However, the changes in students' attitudes and the apparent influence on their final papers and seminars seem to be at least some evidence of the promise of the workbook in such courses as Mathematics and Sport. Future offerings of the course should give further insight into the workbook's usefulness, but at this stage it seems a promising avenue to improve students' learning and their ability to communicate mathematics effectively.

Acknowledgements: The author thanks Harvey Mudd College for a Postdoctoral Fellowship during which the teaching and learning described in this article were undertaken.

\section{References}

[1] J. A. Arter, V. Spandel and R. Culham. Portfolios for assessment and instruction. ERIC Digest [online] 
http://www.ericfacility.net/ericdigests/ed388890.html, 1995. C529, C531, C533, C537

[2] American Mathematical Association of Two-Year Colleges. Crossroads in Mathematics: Standards for Introductory College Mathematics Before Calculus. ed. Don Cohen. [Online] http://www.imacc.org/standards/copyright.html. C531

[3] M. A. Barksdale-Ladd and K. F. Thomas. What's at stake in highstakes testing: teachers and parents speak out, Journal of Teacher Education, 51, 2000, 384-397. doi:10.1177/0022487100051005006 C533

[4] P. A. Brosnan and M. D. Hartog. Approaching standards for mathematics assessment. [Online] http://library.educationworld.net/a9/a9-116.html, 1993. C537

[5] G. Hart, J. Bowden, and J. Watters. Graduate Capabilities: A framework for assessing course quality. Higher Education in Europe, 24(2), 1999, 301-308. http://eprints.qut.edu.au/archive/00001587/ C533

[6] Harvey Mudd College. Highlights. [Online]. http://www.hmc.edu/highlights/, 2003. C528

[7] S. Messick. Validity. In R. L. Linn, editor, Educational Measurement, 3rd ed., American Council on Education, New York, 1989. C533

[8] T. Pandey. Authentic mathematics assessment. Practical Assessment, Research \&6 Evaluation, 2(1) 1990 [Online] http://PAREonline.net/getvn.asp?v=2\&n=1. C529, C530

[9] Quality Assurance Agency for Higher Education (QAAHE). Subject Review Report: University of Warwick - Mathematics, Statistics and Operations Research. [Online]. http://www.qaa.ac.uk/revreps/subj_level/q87_01_textonly.htm. C528 
[10] Saskatchewan Education. Mathematics 10,20: A curriculum guide for the secondary level. Regina, SK: Saskatchewan Education, 1995. http://www.sasked.gov.sk.ca/docs/secmath/secmath.html C534

[11] G. Wiggins. The case for authentic assessment. ERIC Digest [Online]. http://www.ericfacility.net/ericdigests/ed328611.html, 1990. C529 